Article

\title{
Electrodeposition of Vanadium Oxides at Room Temperature as Cathodes in Lithium-Ion Batteries
}

\author{
Michalis Rasoulis ${ }^{1}$ and Dimitra Vernardou ${ }^{2, *}$ \\ 1 Mechanical Engineering Department, Technological Educational Institute of Crete, \\ 71004 Heraklion, Crete, Greece; rasouli1993@hotmail.com \\ 2 Center of Materials Technology and Photonics, School of Applied Technology, \\ Technological Educational Institute of Crete, 71004 Heraklion, Crete, Greece \\ * Correspondence: dimitra@iesl.forth.gr; Tel.: +30-281-037-9774
}

Received: 8 June 2017; Accepted: 11 July 2017; Published: 12 July 2017

\begin{abstract}
Electrodeposition of vanadium pentoxide coatings was performed at room temperature and a short growth period of $15 \mathrm{~min}$ based on an alkaline solution of methanol and vanadyl (III) acetyl acetonate. All samples were characterized by X-ray diffraction, Raman spectroscopy, field-emission scanning electron microscopy, cyclic voltammetry, and electrochemical impedance spectroscopy. The current density and electrolyte concentration were found to affect the characteristics of the as-grown coatings presenting enhanced crystallinity and porous structure at the highest values employed in both cases. The as-grown vanadium pentoxide at current density of $1.3 \mathrm{~mA} \cdot \mathrm{cm}^{-2}$ and electrolyte concentration of $0.5 \mathrm{M}$ indicated the easiest charge transfer of $\mathrm{Li}^{+}$across the vanadium pentoxide/electrolyte interface presenting a specific discharge capacity of $417 \mathrm{mAh} \cdot \mathrm{g}^{-1}$, excellent capacitance retention of $95 \%$, and coulombic efficiency of $94 \%$ after 1000 continuous $\mathrm{Li}^{+}$ intercalation/deintercalation scans. One may then suggest that this route is promising to prepare large area vanadium pentoxide electrodes with excellent stability and efficiency at very mild conditions.
\end{abstract}

Keywords: electrodeposition; $\mathrm{V}_{2} \mathrm{O}_{5}$; room temperature; electrochemical performance

\section{Introduction}

During the last two decades, Li-ion batteries (LIBs) are conquering the markets of portable devices. Although, they have been optimized to meet the requirements of portable electronics, intrinsic characteristics-such as cost, safety, and cycle life-make them less feasible for large scale energy storage systems. The necessity of creating robust and sustainable batteries is the dominant factor of today's market and academic institutions, which would eventually lead to next generation electronics for a greener future.

Among possible electrode materials, metal oxides have attracted a lot of interest due to their ability to form high energy density structures, their relatively high earth abundance, and the lack of any major safety or environmental issues associated with their use. Considering that reactions take place in the entire volume of the materials, the use of nanomaterials is an approach for boosting the performance of the electrodes. In fact, the decrease of metal oxide particle size to the nanoscale level is assumed to result in larger electrode/electrolyte contact areas and the ability to more effectively accommodate the strain of $\mathrm{Li}$ intercalation/deintercalation in nanomaterials [1].

Among the transition metal oxides, vanadium pentoxide $\left(\mathrm{V}_{2} \mathrm{O}_{5}\right)$ is an excellent candidate for redox-dependent applications such as LIBs [2,3]. A great number of strategies have been proposed to develop nanoelectrodes including the self-assembled nanostructures [4], hierarchical 3D mixed conducting networks [5], self-supported nanoarrays with diverse morphologies on 2D/3D conductive substrates as binder-free electrodes [6], 2D nanostructures through dissolution-splitting method from 
their bulk crystal [7], ultrasonic treatment of powders [8], nanocomposites composed of graphene or carbon with actives [9-11], introduction of surface defects by gas annealing [12], and doping by metallic species $[13,14]$. Nevertheless, in some cases, the nanostructured electrodes require complicated fabrication approaches and present poor mechanical stability along with limited rate capability.

Towards this direction, electrodeposition has many benefits since no toxic chemicals are required and it can be employed at low temperatures and pressures. The materials characteristics can be controlled by varying the electrodeposition conditions $[15,16]$ such as current density, time, and electrolyte concentration. In this work, $\mathrm{V}_{2} \mathrm{O}_{5}$ electrodes, without carbon or polymeric binders and metals, were obtained at room temperature from a solution of vanadyl (III) acetyl acetonate $\left(\mathrm{VO}(\mathrm{acac})_{3}\right)$ in methanol $\left(\mathrm{CH}_{3} \mathrm{OH}\right)$ varying the concentration and the current density. The electrochemical properties of the resulting cathodes were examined based on aqueous electrolyte of lithium chloride $(\mathrm{LiCl})$ presenting good cyclic stability and excellent coulombic efficiency after 1000 continuous $\mathrm{Li}^{+}$ intercalation/deintercalation scans. A correlation of the electrodeposited coatings characteristics with their corresponding electrochemical performance is discussed, which is important in terms of the improvement of $\mathrm{Li}^{+}$intercalation mechanisms.

\section{Materials and Methods}

A three-electrode electrochemical cell [17-19] consisting of platinum, $\mathrm{Ag} / \mathrm{AgCl}$ and $\mathrm{SnO}_{2}$ precoated glass substrates as the counter, reference and working electrodes, respectively was utilized for the deposition of $\mathrm{V}_{2} \mathrm{O}_{5}$ coatings. The electrolyte was a solution of $\mathrm{VO}(\mathrm{acac})_{3}$ (Aldrich, Manchester, $\mathrm{UK}, 97 \%$ ) in $\mathrm{CH}_{3} \mathrm{OH}$ (Aldrich, $\mathrm{UK}, 99.8 \%$ ). Prior to electrodeposition, $\mathrm{SnO}_{2}$-precoated glass substrates (Uniglass, Athens, Greece), all $1 \mathrm{~cm} \times 1 \mathrm{~cm} \times 0.3 \mathrm{~cm}$ in dimensions were ultrasonically cleaned with 2-propanol (Aldrich, $\mathrm{UK}, 99.5 \%$ ), acetone (Aldrich, $\mathrm{UK}, 99.9 \%$ ), deionized $\mathrm{H}_{2} \mathrm{O}$ and dried with $\mathrm{N}_{2}$. The growth of $\mathrm{V}_{2} \mathrm{O}_{5}$ was carried out at room temperature using (a) deposition current densities of $0.7,1.0$, and $1.3 \mathrm{~mA} \cdot \mathrm{cm}^{-2}$ for an electrolyte concentration of $0.5 \mathrm{M}$ and (b) electrolyte concentrations of 0.08 , $0.1,0.2$, and $0.5 \mathrm{M}$ for a constant current density of $1.3 \mathrm{~mA} \cdot \mathrm{cm}^{-2}$. The deposition period was $15 \mathrm{~min}$ for both cases. Finally, each freshly deposited sample was dried in air at room temperature.

X-ray diffraction (XRD) measurements were carried out in a Siemens D5000 Diffractometer (SCIMED, Manchester, UK) for $2 \theta=10.00^{\circ}-50.00^{\circ}$, step-size $=0.02^{\circ}$ and step time $=30 \mathrm{~s} /{ }^{\circ}$. Raman measurements were performed in a Nicolet Almega XR micro-Raman system (CRAIC, Hertfordshire, UK) operating at wavenumber range of $100-1200 \mathrm{~cm}^{-1}$ using a $473 \mathrm{~nm}$ laser. Regarding the morphology of the samples, the analysis was carried out in a Jeol JSM-7000F field-emission scanning electron microscopy (FE-SEM, Zaventem, Belgium). Prior to FE-SEM analysis, samples were over-coated with a thin film of gold to prevent charging. Finally, cyclic voltammetry experiments were performed in the same set-up utilized for electrodeposition. The electrolyte was an aqueous solution of $1 \mathrm{M}, \mathrm{LiCl}$ (Aldrich, UK, $\geq 99.0 \%$ ) for a number of scans up to 1000 , a scan rate of $10 \mathrm{mV} \cdot \mathrm{s}^{-1}$ through the potential range of $-1.2-0 \mathrm{~V}$. The galvanostatic curves were obtained at a constant specific current of $1 \mathrm{~A} \cdot \mathrm{g}^{-1}$ and a potential range of -0.1 to $-0.65 \mathrm{~V}$ for a total period of $1000 \mathrm{~s}$. Furthermore, the electrochemical impedance spectroscopy (EIS) curves were obtained at AC amplitude of $-0.6 \mathrm{~V}$ and a set potential of $0 \mathrm{~V}$ over the frequency range of $10 \mathrm{mHz}-35 \mathrm{kHz}$.

Finally, the coating's thickness was estimated using a profilometer A-step TENCOR (KLA Tencor, Dublin, Ireland) by etching the $\mathrm{V}_{2} \mathrm{O}_{5}$ coatings off the $\mathrm{SnO}_{2}$ glass substrate in 1:3, $\mathrm{H}_{2} \mathrm{O}_{2}(30 \%): \mathrm{HCl}$ and thickness was deduced from the measured step height.

\section{Results and Discussion}

The yellow electrodeposited $\mathrm{V}_{2} \mathrm{O}_{5}$ coatings had similar properties (structural and electrochemical) after approximately six months, indicating their stability over time. 


\subsection{Structure}

Figure 1 shows a representative XRD pattern of the electrodeposited $\mathrm{V}_{2} \mathrm{O}_{5}$ coatings. It exhibits three characteristic $2 \theta$ values at $19.9^{\circ}, 32.2^{\circ}$, and $45.8^{\circ}$ with respective Miller indices (001), (400), and (411), which are consistent with crystalline $\mathrm{V}_{2} \mathrm{O}_{5}$ [20]. The peaks intensity was varied depending on the thickness of the coatings. Additionally, there is no vanadium oxide peak for the electrodeposited coatings using electrolyte concentration of $0.08 \mathrm{M}$ and current density of $1.3 \mathrm{~mA} \cdot \mathrm{cm}^{-2}$, indicating its amorphous character.

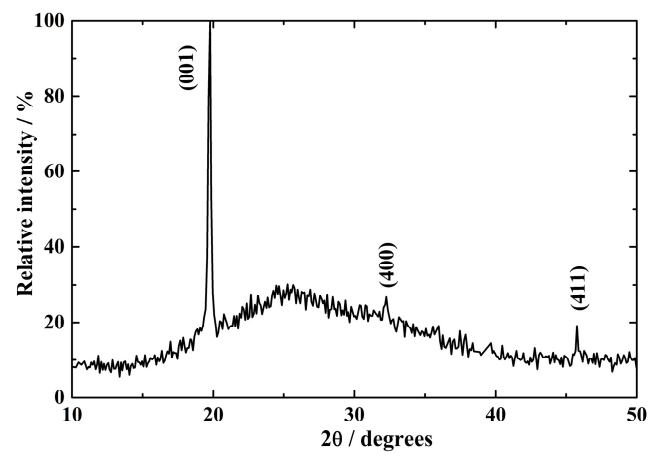

Figure 1. XRD pattern of the electrodeposited $\mathrm{V}_{2} \mathrm{O}_{5}$ coatings on $\mathrm{SnO}_{2}$-precoated glass substrates using current density of $1.3 \mathrm{~mA} \mathrm{~cm}^{-2}$ and electrolyte concentration of $0.5 \mathrm{M}$ for a growth period of $15 \mathrm{~min}$ at room temperature.

In order to verify XRD results, Raman spectroscopy was also accomplished. Figure 2 displays the Raman spectra of electrodeposited $\mathrm{V}_{2} \mathrm{O}_{5}$ coatings for current densities of $0.7,1.0,1.3 \mathrm{~mA} \cdot \mathrm{cm}^{-2}$ and electrolyte concentration of $0.5 \mathrm{M}$ along with the electrolyte concentrations of 0.1 and $0.2 \mathrm{M}$ for $1.3 \mathrm{~mA} \cdot \mathrm{cm}^{-2}$. The peak positions agree with the literature [21-24].
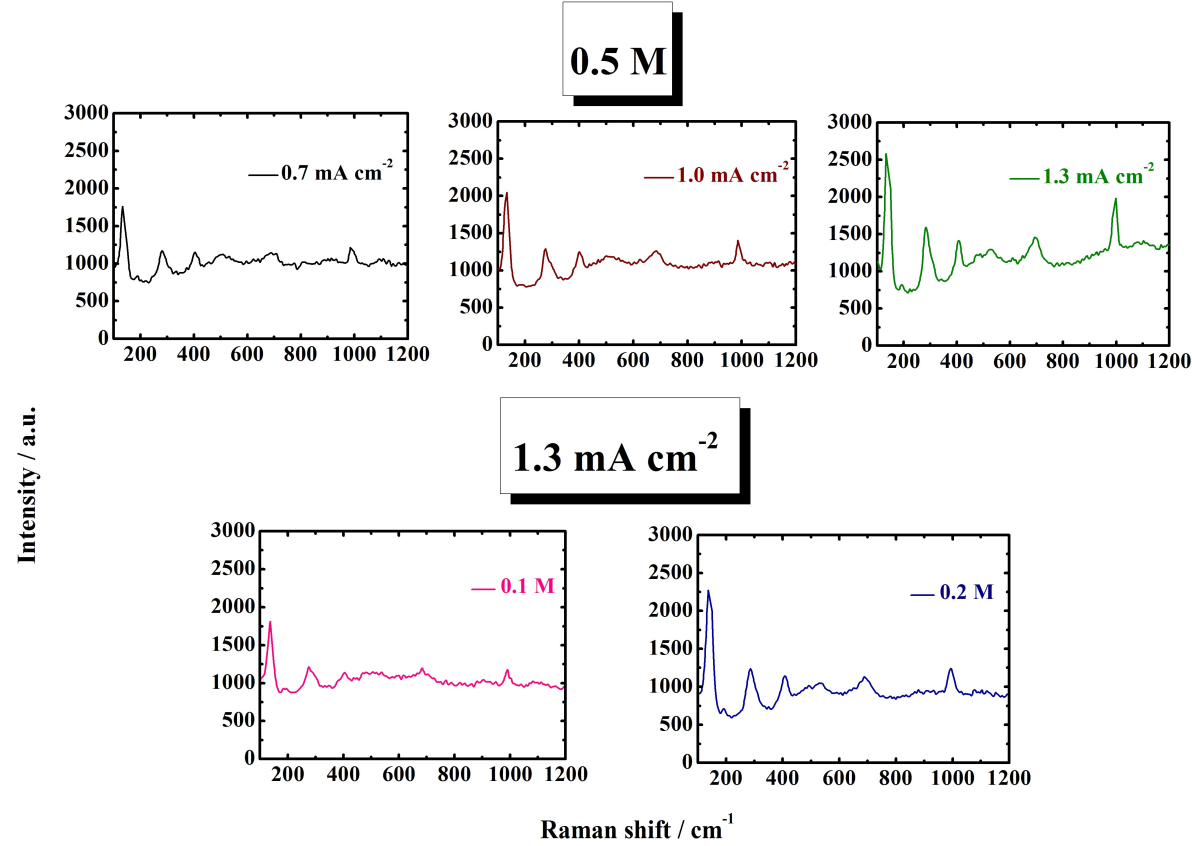

Figure 2. Raman spectra of the electrodeposited $\mathrm{V}_{2} \mathrm{O}_{5}$ for current densities of $0.7,1.0,1.3 \mathrm{~mA} \mathrm{~cm}^{-2}$ at a constant electrolyte concentration of $0.5 \mathrm{M}$ and for electrolyte concentrations of 0.1 and $0.2 \mathrm{M}$ at $1.3 \mathrm{~mA} \mathrm{~cm}^{-2}$. 
Such outcomes suggest that the peaks intensity increases with increasing current density and electrolyte concentration, which means crystallinity of the electrodeposited $\mathrm{V}_{2} \mathrm{O}_{5}$ coatings is improved. This happens because for a certain time interval, when the current applied to the electrodeposition is increased, the amount of material should also increase according to Faraday's first law. Accordingly, when the concentration of a solution increases, the particles are more crowded and the number of effective collision per unit of time is higher. It is then possible to define the electrodeposition parameters wherein single-phase highly crystalline $\mathrm{V}_{2} \mathrm{O}_{5}$ may be formed: current density of $1.3 \mathrm{~mA} \cdot \mathrm{cm}^{-2}$, electrolyte concentration of $0.5 \mathrm{M}$, deposition period of $15 \mathrm{~min}$ at room temperature. These parameters are expected to directly influence the characteristics of the electrodeposited coatings and promote their up-scale.

The growth rate of the electrodeposited coatings was estimated from the deposition time and the coating's thickness as determined from the profilometer. The highest value was $5.3 \mathrm{~nm} \cdot \mathrm{min}^{-1}$ for electrolyte concentration of $0.5 \mathrm{M}$ at $1.3 \mathrm{~mA} \cdot \mathrm{cm}^{-2}$. As the current density decreases to $0.7 \mathrm{~mA} \cdot \mathrm{cm}^{-2}$, the growth rate estimated to be $2.7 \mathrm{~nm} \cdot \mathrm{min}^{-1}$ indicating that there was no efficient deposition for current density $<1.3 \mathrm{~mA} \cdot \mathrm{cm}^{-2}$. An analogous behavior occurs as the electrolyte concentration decreases to $0.2 \mathrm{M}$, reaching a value of $2.2 \mathrm{~nm} \cdot \mathrm{min}^{-1}$. These values are in agreement with the observations obtained from XRD and Raman spectroscopy (i.e., lower peak intensities for lower current densities and electrolyte concentrations).

\subsection{Morphology}

The electrodeposited $\mathrm{V}_{2} \mathrm{O}_{5}$ electrodes at various current densities and electrolyte concentrations were examined using FE-SEM; the obtained micrographs are shown in Figures 3 and 4, respectively. At $1.3 \mathrm{~mA} \cdot \mathrm{cm}^{-2}$ for electrolyte concentration of $0.5 \mathrm{M}$, the prepared oxide consisted of agglomerated nanoparticles forming a porous structure (Figure 3c). As the current density decreased to 0.7 (Figure 3a) and $1.0 \mathrm{~mA} \cdot \mathrm{cm}^{-2}$ (Figure $3 \mathrm{~b}$ ), the oxide became condensed and cracks appeared for the lowest current density applied. A similar behavior was observed when the electrolyte concentration decreased to 0.1 (Figure 4a) and $0.2 \mathrm{M}$ (Figure $4 \mathrm{~b}$ ) at a constant current density. All combine to an apparent increase of the oxide's active volume with current density and electrolyte concentration i.e., accessible to charge through the porous morphology.

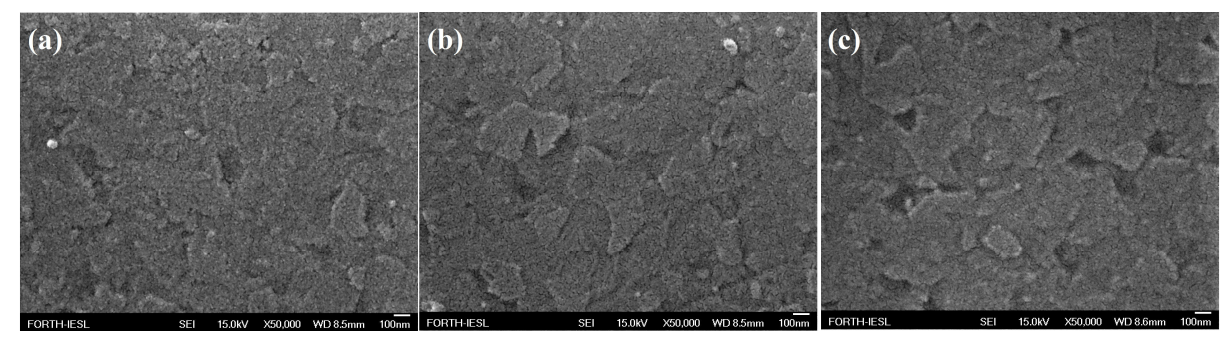

Figure 3. FE-SEM images of the electrodeposited $\mathrm{V}_{2} \mathrm{O}_{5}$ for current densities of $0.7(\mathbf{a}), 1.0(\mathbf{b})$, and $1.3 \mathrm{~mA} \cdot \mathrm{cm}^{-2}$ (c) at a constant electrolyte concentration of $0.5 \mathrm{M}$ for a magnification of $\times 50,000$.

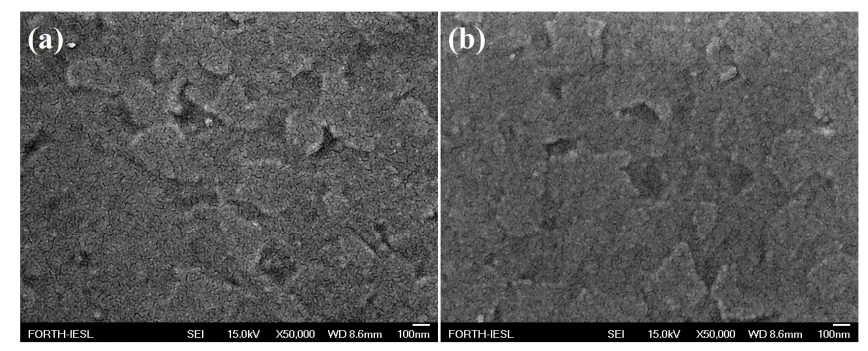

Figure 4. FE-SEM images of the electrodeposited $\mathrm{V}_{2} \mathrm{O}_{5}$ for electrolyte concentrations of 0.1 (a) and $0.2 \mathrm{M}(\mathbf{b})$ at $1.3 \mathrm{~mA} \cdot \mathrm{cm}^{-2}$ for a magnification of $\times 50,000$. 


\subsection{Electrochemical Performance}

\section{Cyclic Voltammetry}

The effect of current density on the electrochemical properties of the electrodeposited $\mathrm{V}_{2} \mathrm{O}_{5}$ was examined by cyclic voltammetry as indicated in Figure $5 \mathrm{a}$. The scan rate was $10 \mathrm{mV} \cdot \mathrm{s}^{-1}$ through the potential range of $-1.2-0 \mathrm{~V}$. It is indicated that the current density of the as-grown $\mathrm{V}_{2} \mathrm{O}_{5}$ at room temperature for electrolyte concentration of $0.5 \mathrm{M}$ at $1.3 \mathrm{~mA} \cdot \mathrm{cm}^{-2}$ is the highest presenting enhanced electrochemical activity. Only this sample showed stability after 1000 continuous $\mathrm{Li}^{+}$ intercalation/deintercalation scans - as indicated from the similarity of the red and black curve in Figure 5a inset-and the morphology's preservation without obvious damage (Figure 5b) compared with the pristine sample (Figure 3c). Regarding the other as-grown coatings, detachment of the oxide by the electrolyte was observed after a few scans (the working electrode was optically the same with the substrate prior to deposition). Similar observations were observed for the electrodeposited $\mathrm{V}_{2} \mathrm{O}_{5}$ coatings for 0.1 and $0.2 \mathrm{M}$ at $1.3 \mathrm{~mA} \cdot \mathrm{cm}^{-2}$. Since, the electrochemical cell is made up of glass, these changes could be observed during the electrochemical measurements. This observation is consistent with reports that amorphous materials dissolve more easily than crystallized ones during $\mathrm{Li}^{+}$intercalation/deintercalation processes [25], strengthening the stability of the electrodeposited $\mathrm{V}_{2} \mathrm{O}_{5}$ for electrolyte concentration of $0.5 \mathrm{M}$ at $1.3 \mathrm{~mA} \cdot \mathrm{cm}^{-2}$ with improved crystallinity.

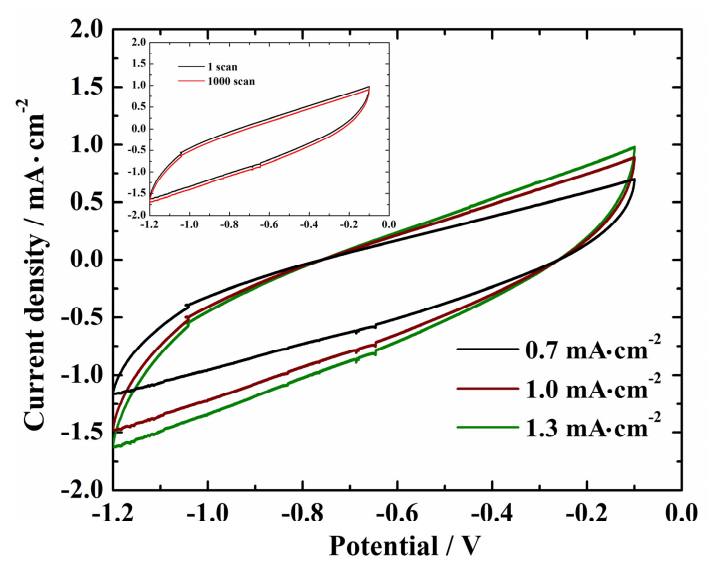

(a)

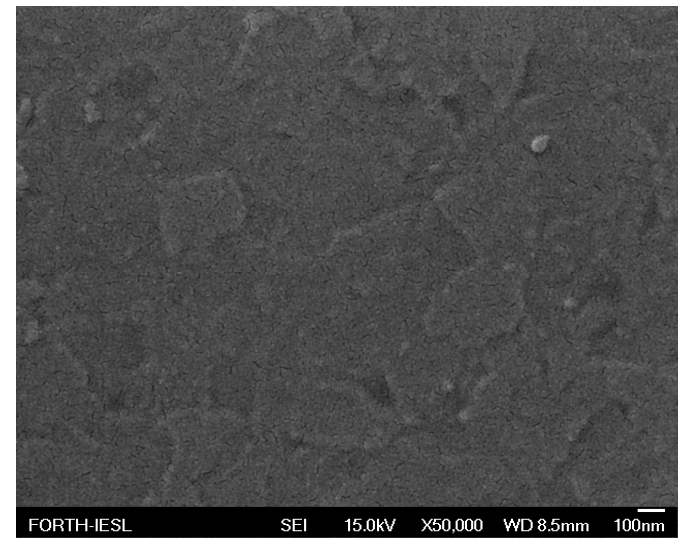

(b)

Figure 5. Cyclic voltammograms of electrodeposited $\mathrm{V}_{2} \mathrm{O}_{5}$ at room temperature for current densities of $0.7,1.0,1.3 \mathrm{~mA} \cdot \mathrm{cm}^{-2}$ at a constant electrolyte concentration of $0.5 \mathrm{M}$ (cyclic voltammograms of $\mathrm{V}_{2} \mathrm{O}_{5}$ at current density of $1.3 \mathrm{~mA} \mathrm{~cm}^{-2}$ for the $1 \mathrm{st}$ and the 1000th scan as inset) (a). FE-SEM image of the electrodeposited $\mathrm{V}_{2} \mathrm{O}_{5}$ for a current density of $1.3 \mathrm{~mA} \cdot \mathrm{cm}^{-2}$ after 1000 scans (b).

The charge/discharge curves at a specific current of $1 \mathrm{~A} \cdot \mathrm{g}^{-1}$ and potential ranging -0.65 to $-0.1 \mathrm{~V}$ vs. $\mathrm{Ag} / \mathrm{AgCl}$ of the as-grown $\mathrm{V}_{2} \mathrm{O}_{5}$ coatings using $0.7,1.0$, and $1.3 \mathrm{~mA} \cdot \mathrm{cm}^{-2}$ for an electrolyte concentration of $0.5 \mathrm{M}$ are shown in Figure 6. The mass of the electrodeposited oxides was measured by a five-digit analytical grade scale obtained by measuring the $\mathrm{SnO}_{2}$-precoated glass substrate before and after the growth. It was found to be $0.00005,0.00007,0.00012 \mathrm{~g}$ for $0.7,1.0$, and $1.3 \mathrm{~mA} \cdot \mathrm{cm}^{-2}$, respectively. The bent charge and discharge curves of all samples can be attributable to the high interfacial resistance at the interface between the electrode and the electrolyte. The specific discharge capacity of $\mathrm{V}_{2} \mathrm{O}_{5}$ for $1.3 \mathrm{~mA} \cdot \mathrm{cm}^{-2}$ was $417 \mathrm{mAh} \cdot \mathrm{g}^{-1}$ with capacitance retention of $95 \%$ and coulombic efficiency of $94 \%$ after 1000 continuous $\mathrm{Li}^{+}$intercalation/deintercalation scans. Thus, excellent cycle lifetime and efficiency are presented for this sample due to enhanced crystallinity and surface contributions as it possibly has higher interfacial area and thus can maintain more contact with the electrolyte (due to the highest thickness and the porous morphology). This facilitates better $\mathrm{Li}^{+}$ diffusion to the active material, which consequently improves material accessibility and reduces ohmic 
resistance due to better electrical contact with the current collector $\left(\mathrm{SnO}_{2}\right.$-precoated glass substrate). The estimated specific discharge capacity is comparable with nanoparticles employing rice husk carbon as templates $\left(250 \mathrm{mAh} \cdot \mathrm{g}^{-1}\right.$ [26]), nanostructured hollow microspheres (195 $\mathrm{mAh} \cdot \mathrm{g}^{-1}$ [27]), nanoribbons (200 $\mathrm{mAh} \cdot \mathrm{g}^{-1}$ [28]), and porous nanostructured $\mathrm{V}_{2} \mathrm{O}_{5}\left(325 \mathrm{mAh} \cdot \mathrm{g}^{-1}\right.$ [29]). One may then say that the process followed in this work is promising to prepare large area $\mathrm{V}_{2} \mathrm{O}_{5}$ electrodes with excellent stability and efficiency at very mild conditions including the deposition temperature at room temperature, quick deposition period, and aqueous electrolytes.

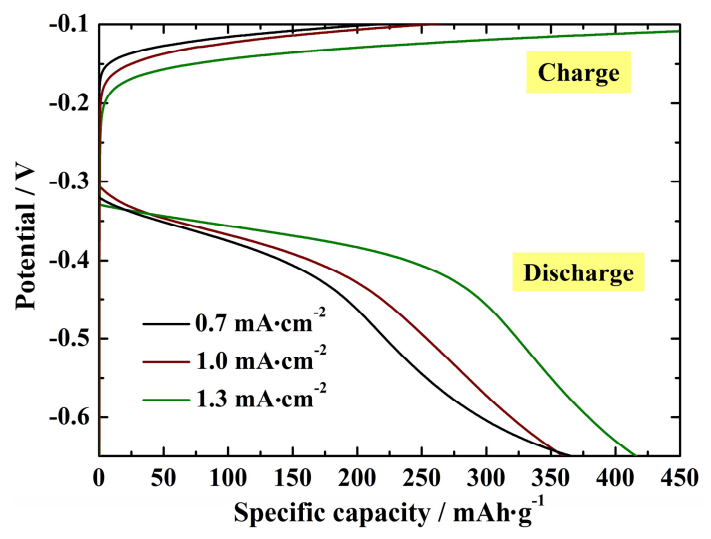

Figure 6. Charge/discharge curves at a specific current of $1 \mathrm{~A} \cdot \mathrm{g}^{-1}$ for the electrodeposited $\mathrm{V}_{2} \mathrm{O}_{5}$ coatings at room temperature using $0.7,1.0,1.3 \mathrm{~mA} \cdot \mathrm{cm}^{-2}$ at a constant electrolyte concentration of $0.5 \mathrm{M}$.

The effect of current density on the electron transport and recombination properties of the electrodeposited $\mathrm{V}_{2} \mathrm{O}_{5}$ coatings is examined using a frequency response analysis in the range from $10 \mathrm{mHz}$ to $35 \mathrm{kHz}$ as shown in Figure 7. The symbols present the experimental data, while the solid lines, the results fitted by Z view software (FRA32M, Metrohm Autolab, Utrecht, The Netherlands). The equivalent circuit utilized to fit the plots is indicated in Figure 7 inset, which consists of a solution resistance $\left(R_{\mathrm{s}}\right)$, a charge transfer resistance across the interface $\left(R_{\mathrm{p}}\right)$, and a constant phase element. All plots show semicircles, which correspond to the charge transfer reaction at the electrode/electrolyte interface $[30,31]$. The smaller the diameter of the semicircle is, the smaller the charge transfer resistance will be, indicating that the electrodeposited $\mathrm{V}_{2} \mathrm{O}_{5}$ for current density of $1.3 \mathrm{~mA} \cdot \mathrm{cm}^{-2}(145 \Omega)$ is beneficial for charge transfer across the electrode/electrolyte interface.

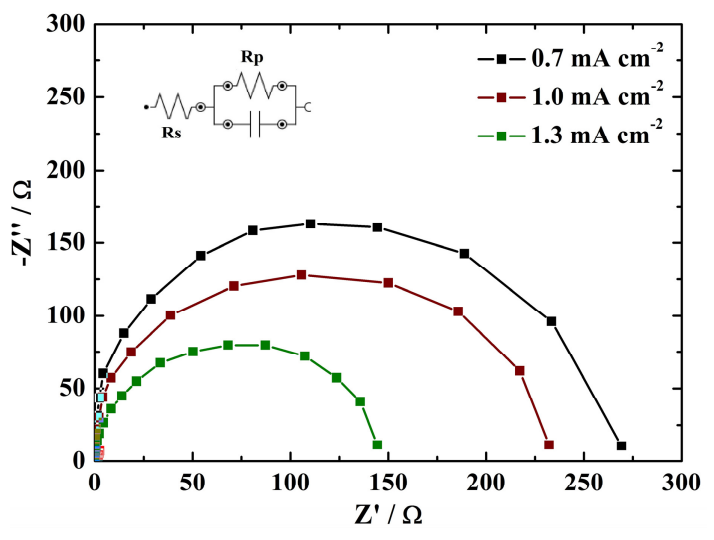

Figure 7. Nyquist plots of the measured (symbols) and fitted (line) impedance spectra of the electrodeposited $\mathrm{V}_{2} \mathrm{O}_{5}$ at room temperature for current density of $0.7,1.0$, and $1.3 \mathrm{~mA} \cdot \mathrm{cm}^{-2}$ at a constant electrolyte concentration of $0.5 \mathrm{M}$. Equivalent circuit is indicated as inset. 


\section{Conclusions}

Electrodeposited $\mathrm{V}_{2} \mathrm{O}_{5}$ coatings were prepared at room temperature without surfactants, carbon or polymeric binders and metals, but simply based on an alkaline solution of $\mathrm{CH}_{3} \mathrm{OH}$ and $\mathrm{VO}(\mathrm{acac})_{3}$. Structural analysis indicated the enhanced crystalline quality of the coatings as the current density and electrolyte concentration increased. Morphology of the as-grown coatings was also affected, indicating cracks at the lowest current density employed, while at $1.3 \mathrm{~mA} \cdot \mathrm{cm}^{-2}$ agglomerated nanoparticles eventually appeared, forming a porous structure. A similar behavior was observed as a function of the electrolyte concentration. The electrode material for current density of $1.3 \mathrm{~mA} \cdot \mathrm{cm}^{-2}$ showed the best performance including a specific discharge capacity of $417 \mathrm{mAh} \cdot \mathrm{g}^{-1}$ with excellent capacitance retention of $95 \%$ and coulombic efficiency of $94 \%$ after 1000 continuous $\mathrm{Li}^{+}$ intercalation/deintercalation scans under a specific current of $1 \mathrm{~A} \cdot \mathrm{g}^{-1}$. This improved performance is ought to the enhanced crystallinity and surface contributions (highest thickness and porous morphology), which facilitate better $\mathrm{Li}^{+}$diffusion to the active material reducing ohmic resistance.

Author Contributions: Michalis Rasoulis performed the cyclic voltammetry and electrochemical impedance spectroscopy analysis; Dimitra Vernardou designed the electrodeposition experiments and carried out the structural/morphological characterization.

Conflicts of Interest: The authors declare no conflict of interest.

\section{References}

1. Bruce, P.G.; Scrosati, B.; Tarascon, J.-M. Nanomaterials for rechargeable lithium batteries. Angew. Chem. Int. Ed. 2008, 47, 2930-2946. [CrossRef] [PubMed]

2. Gupta, S.; Aberg, B.; Carrizosa, S.B.; Dimakis, N. Vanadium pentoxide nanobelt-reduced graphene oxide nanosheet as high-performance pseudocapacitive electrodes: AC impedance spectroscopy data modeling and theoretical calculations. Materials 2016, 9, 615. [CrossRef]

3. Li, H.; Wang, J.; Liu, X.; Sun, Q.; Djuri, A.B.; Xie, M.; Mei, Y.; Tang, C.Y.; Shih, K. Template-free synthesis of hierarchical hollow $\mathrm{V}_{2} \mathrm{O}_{5}$ microspheres with highly stable lithium storage capacity. RSC Adv. 2017, 7, 2480-2485. [CrossRef]

4. Cao, A.M.; Hu, J.S.; Liang, H.P.; Wan, L.J. Self-assembled vanadium pentoxide $\left(\mathrm{V}_{2} \mathrm{O}_{5}\right)$ hollow microspheres from nanorods and their application in lithium-ion batteries. Angew. Chem. Int. Ed. 2005, 44, 4391-4395. [CrossRef] [PubMed]

5. Armstrong, E.; McNulty, D.; Geaney, H.; O’Dwyer, C. Electrodeposited structurally stable $\mathrm{V}_{2} \mathrm{O}_{5}$ inverse opal networks as high performance thin film lithium batteries. ACS Appl. Mater. Inter. 2015, 7, 27006-27015. [CrossRef] [PubMed]

6. Zhang, F.; Qi, L. Recent progress in self-supported metal oxide nanoarray electrodes for advanced lithium-ion batteries. Adv. Sci. 2016, 3, 1600049. [CrossRef] [PubMed]

7. Wang, Z.; Xu, D.; Wang, L.; Zhang, X. Facile and low-cost synthesis of large-area pure $\mathrm{V}_{2} \mathrm{O}_{5}$ nanosheets for high-capacity and high-rate lithium storage over a wide temperature range. Chem. Plus. Chem. 2012, 77, 124-128. [CrossRef]

8. Li, Y.; Yao, J.; Uchaker, E.; Yang, J.; Huang, Y.; Zhang, M.; Cao, G. Leaf-like $\mathrm{V}_{2} \mathrm{O}_{5}$ nanosheets fabricated by a facile green approach as high energy material for lithium-ion batteries. Adv. Energy Mater. 2013, 3, 1171-1175. [CrossRef]

9. Armstrong, M.J.; Burke, D.M.; Gabriel, T.; O’Regan, C.; O’Dwyer, C.; Petkov, N.; Holmes, J.D. Carbon nanocage supported synthesis of $\mathrm{V}_{2} \mathrm{O}_{5}$ nanorods and $\mathrm{V}_{2} \mathrm{O}_{5} / \mathrm{TiO}_{2}$ nanocomposites for Li-ion batteries. J. Mater. Chem. A 2013, 1, 12568-12578. [CrossRef]

10. Sathiya, M.; Prakash, A.S.; Pamesha, K.; Tarascon, J.M.; Shukla, A.K. $\mathrm{V}_{2} \mathrm{O}_{5}$-anchored carbon nanotubes for enhanced electrochemical energy storage. J. Am. Chem. Soc. 2011, 133, 16291-16299. [CrossRef] [PubMed]

11. Jiang, J.; Li, Y.; Liu, J.; Huang, X.; Yuan, C.; Xiong, W.L. Recent advances in metal oxide-based electrode architecture design for electrochemical energy storage. Adv. Mater. 2012, 24, 5166-5180. [CrossRef] [PubMed] 
12. Liu, D.W.; Liu, Y.Y.; Garcia, B.B.; Zhang, Q.F.; Pan, A.Q.; Jeong, Y.H.; Cao, G.Z. $\mathrm{V}_{2} \mathrm{O}_{5}$ xerogel electrodes with much enhanced lithium-ion intercalation properties with $\mathrm{N}_{2}$ annealing. J. Mater. Chem. 2009, 19, 8789-8795. [CrossRef]

13. Khoo, E.; Wang, J.M.; Ma, J.; Lee, P.S. Electrochemical energy storage in a $\beta-\mathrm{Na}_{0.33} \mathrm{~V}_{2} \mathrm{O}_{5}$ nanobelt and its application for supercapacitors. J. Mater. Chem. 2010, 20, 8368-8374. [CrossRef]

14. Lai, C.-H.; Lin, C.-K.; Lee, S.-W.; Li, H.-Y.; Chang, J.-K.; Deng, M.-J. Nanostructured Na-doped vanadium oxide synthesized using an anodic deposition technique for supercapacitor applications. J. Alloy Compd. 2012, 536, S428-S431. [CrossRef]

15. Drosos, H.; Sapountzis, A.; Koudoumas, E.; Katsarakis, N.; Vernardou, D. Effect of deposition current density on electrodeposited vanadium oxide coatings. J. Electrochem. Soc. 2012, 159, E145-E147. [CrossRef]

16. Vernardou, D.; Sapountzis, A.; Spanakis, E.; Kenanakis, G.; Koudoumas, E.; Katsarakis, N. Electrochemical activity of electrodeposited $\mathrm{V}_{2} \mathrm{O}_{5}$ coatings. J. Electrochem. Soc. 2013, 160, D6-D9. [CrossRef]

17. Louloudakis, D.; Vernardou, D.; Spanakis, E.; Katsarakis, N.; Koudoumas, E. Electrochemical properties of vanadium oxide coatings grown by APCVD on glass substrates. Surf. Coat. Technol. 2013, 230, 186-189. [CrossRef]

18. Vernardou, D.; Louloudakis, D.; Spanakis, E.; Katsarakis, N.; Koudoumas, E. Electrochemical properties of vanadium oxide coatings grown by hydrothermal synthesis on FTO substrates. New J. Chem. 2014, 38, 1959-1964. [CrossRef]

19. Vernardou, D.; Apostolopoulou, M.; Louloudakis, D.; Katsarakis, N.; Koudoumas, E. Hydrothermally grown $\beta-\mathrm{V}_{2} \mathrm{O}_{5}$ electrode at $95^{\circ} \mathrm{C}$. J. Colloid. Interf. Sci. 2014, 424, 1-6. [CrossRef] [PubMed]

20. Su, Q.; Huang, C.K.; Wang, Y.; Fan, Y.C.; Lu, B.A.; Lan, W.; Wang, Y.Y.; Liu, X.Q. Formation of vanadium oxides with various morphologies by chemical vapor deposition. J. Alloys Comp. 2009, 475, 518-523. [CrossRef]

21. Lee, S.-H.; Cheong, H.M.; Je Seong, M.; Liu, P.; Tracy, C.E.; Mascarenhas, A.; Pitts, J.R.; Deb, S.K. Raman spectroscopic studies of amorphous vanadium oxide thin films. Solid State Ionics 2003, 165, 111-116. [CrossRef]

22. Abello, L.; Husson, E.; Repelin, Y.; Lucazeau, G. Vibrational spectra and valence force field of crystalline $\mathrm{V}_{2} \mathrm{O}_{5}$. Spectrochim. Acta A-M. 1983, 39, 641-651. [CrossRef]

23. Julien, C.; Nazri, G.A.; Bergström, O. Raman scattering studies of microcrystalline $\mathrm{V}_{6} \mathrm{O}_{13}$. Phys. Status Solidi 1997, 201, 319-326. [CrossRef]

24. Jehng, J.M.; Hardcastle, F.D.; Wachs, I.E. The interaction of $\mathrm{V}_{2} \mathrm{O}_{5}$ and $\mathrm{Nb}_{2} \mathrm{O}_{5}$ with oxide surface. Solid State Ionics 1989, 32/33, 904-910. [CrossRef]

25. Ng, S.H.; Chew, S.Y.; Wang, J.; Wexler, D.; Tournayre, Y.; Konstantinov, K.; Liu, H.K. Synthesis and electrochemical properties of $\mathrm{V}_{2} \mathrm{O}_{5}$ nanostructures prepared via a precipitation process for lihium-ion battery cathodes. J. Power Sources 2007, 174, 1032-1035. [CrossRef]

26. Zhu, K.; Meng, Y.; Qiu, H.; Gao, Y.; Wang, C.; Du, F.; Wei, Y.; Chen, G. Facile synthesis of $\mathrm{V}_{2} \mathrm{O}_{5}$ nanoparticles as a capable cathode for high energy lithium-ion batteries. J. Alloy Comp. 2015, 650, 370-373. [CrossRef]

27. Uchaker, E.; Zhou, N.; Li, Y.; Cao, G. Polyol-mediated solvothermal synthesis and electrochemical performance of nanostructured $\mathrm{V}_{2} \mathrm{O}_{5}$ hollow microspheres. J. Phys. Chem. C 2013, 117, 1621-1625. [CrossRef]

28. Tartaj, P.; Amarilla, J.M.; Vazquez-Santos, M.B. Surfactant-free vanadium oxides from reverse micelles and organic oxidants: Solution processable nanoribbons with potential applicability as battery insertion electrodes assembled in different configurations. Langmuir 2015, 31, 12489-12496. [CrossRef] [PubMed]

29. Liu, Y.; Li, J.; Zhang, Q.; Zhou, N.; Uchaker, E.; Cao, G. Porous nanostructured $\mathrm{V}_{2} \mathrm{O}_{5}$ film electrode with excellent Li-ion intercalation properties. Electrochem. Commun. 2011, 13, 1276-1279. [CrossRef]

30. Qin, J.; Lv, Z.; Li, Z.; Li, B.; Kang, F.; Yang, Q.-H. An interlaced silver vanadium oxide-graphene hybrid with high structural stability for use in lithium ion batteries. Chem. Commun. 2014, 50, 13447-13450. [CrossRef] [PubMed]

31. Wu, Y.; Zhu, P.; Zhao, X.; Reddy, M.V.; Peng, S.; Chowdari, B.V.R.; Ramakrishna, S. Highly improved rechargeable stability for lithium/silver vanadium oxide battery induced via electrospinning technique. J. Mater. Chem. A 2013, 1, 852-859. [CrossRef]

(C) 2017 by the authors. Licensee MDPI, Basel, Switzerland. This article is an open access article distributed under the terms and conditions of the Creative Commons Attribution (CC BY) license (http:/ / creativecommons.org/licenses/by/4.0/). 